DISTRIBUTION STATEMENT A. Approved for public release; distribution is unlimited.

\title{
ESPC-2 Operational Implementation and Validation of the Coupled System
}

\author{
E. Joseph Metzger \\ Naval Research Laboratory, Code 7323 \\ Stennis Space Center, MS 39529-5004 \\ phone: (228) 688-4762 fax:(228)688-4759 email: joe.metzger@nrlssc.navy.mil \\ Benjamin C. Ruston \\ Naval Research Laboratory, Code 7531 \\ Monterey, CA 93943 \\ phone: (831) 656-4020 fax: (831) 656-4769 email: ben.ruston@nrlmry.navy.mil \\ Award Number: N0001414WX20053 \\ http://www7320.nrlssc.navy.mil/GLBhycom1-12/skill.html \\ http://www.usno.navy.mil/FNMOC/
}

\section{LONG-TERM GOALS}

A fully coupled global atmosphere/ocean/ice/wave/land prediction system providing daily predictions out to 10 days and weekly predictions out to 30 days.

\section{OBJECTIVES}

The first objective is designing the infrastructure for operational implementation of the fully coupled global system. This design includes scoping the system to fit within the constraints of the operational centers. These constraints include both computational and manpower resources. Determination of the run cycle will take into account the three main forecasts (10-day deterministic, 30-day deterministic and 90-day probabilistic) with data assimilation for the different components to be considered. Data streams, inputs and post-processing also will be considered.

The second objective is the validation of the three primary forecasts. The validation will be conducted relative to traditional metrics that have been used in prior transitions of individual ESPC components. In addition, the ESPC forecasts will be validated against the ESPC demonstration goals.

\section{APPROACH}

\section{Work area: Design infrastructure for operational implementation for coupled system}

The supporting infrastructure development will begin to cycle with the data assimilation of each component, provide the appropriate daily hindcasts, include the analysis insertion as appropriate. The first step will be a loosely coupled DA system with data assimilation carried out separately for individual components at the initial time. The exchange variables between components will be adjusted to ensure consistency and balance as necessary. This will be controlled by the scheduling of 


\section{Report Documentation Page}

Form Approved

OMB No. 0704-0188

Public reporting burden for the collection of information is estimated to average 1 hour per response, including the time for reviewing instructions, searching existing data sources, gathering and maintaining the data needed, and completing and reviewing the collection of information. Send comments regarding this burden estimate or any other aspect of this collection of information,

including suggestions for reducing this burden, to Washington Headquarters Services, Directorate for Information Operations and Reports, 1215 Jefferson Davis Highway, Suite 1204, Arlington

VA 22202-4302. Respondents should be aware that notwithstanding any other provision of law, no person shall be subject to a penalty for failing to comply with a collection of information if it

does not display a currently valid OMB control number.

\begin{tabular}{|c|c|c|}
\hline $\begin{array}{l}\text { 1. REPORT DATE } \\
\text { 30 SEP } 2014\end{array}$ & 2. REPORT TYPE & $\begin{array}{l}\text { 3. DATES COVERED } \\
\mathbf{0 0 - 0 0 - 2 0 1 4} \text { to 00-00-2014 }\end{array}$ \\
\hline \multirow{3}{*}{\multicolumn{2}{|c|}{$\begin{array}{l}\text { ESPC-2 Operational Implementation and Validation of the Coupled } \\
\text { System }\end{array}$}} & 5a. CONTRACT NUMBER \\
\hline & & 5b. GRANT NUMBER \\
\hline & & 5c. PROGRAM ELEMENT NUMBER \\
\hline \multirow{3}{*}{\multicolumn{2}{|c|}{ 6. AUTHOR(S) }} & 5d. PROJECT NUMBER \\
\hline & & 5e. TASK NUMBER \\
\hline & & 5f. WORK UNIT NUMBER \\
\hline \multicolumn{2}{|c|}{$\begin{array}{l}\text { 7. PERFORMING ORGANIZATION NAME(S) AND ADDRESS(ES) } \\
\text { Naval Research Laboratory,Code 7323,Stennis Space Center,MS,39529 }\end{array}$} & $\begin{array}{l}\text { 8. PERFORMING ORGANIZATION } \\
\text { REPORT NUMBER }\end{array}$ \\
\hline \multirow{2}{*}{\multicolumn{2}{|c|}{ 9. SPONSORING/MONITORING AGENCY NAME(S) AND ADDRESS(ES) }} & 10. SPONSOR/MONITOR'S ACRONYM(S) \\
\hline & & $\begin{array}{l}\text { 11. SPONSOR/MONITOR'S REPORT } \\
\text { NUMBER(S) }\end{array}$ \\
\hline
\end{tabular}

12. DISTRIBUTION/AVAILABILITY STATEMENT

Approved for public release; distribution unlimited

13. SUPPLEMENTARY NOTES

14. ABSTRACT

15. SUBJECT TERMS

16. SECURITY CLASSIFICATION OF:

\begin{tabular}{c|c|c|}
$\begin{array}{c}\text { a. REPORT } \\
\text { unclassified }\end{array}$ & $\begin{array}{c}\text { b. ABSTRACT } \\
\text { unclassified }\end{array}$ & $\begin{array}{c}\text { c. THIS PAGE } \\
\text { unclassified }\end{array}$
\end{tabular}

17. LIMITATION OF ABSTRACT

Same as

Report (SAR)

\begin{tabular}{c|l}
$\begin{array}{c}\text { 18. NUMBER } \\
\text { OF PAGES } \\
\mathbf{7}\end{array}$ & 19a. NAME OF \\
& \\
&
\end{tabular}


individual jobs. As the truly coupled DA system developed under separate projects become available and maturing, it will be integrated into the full execution of the total system, ready for the ESPC demonstration.

Work area: Validation testing relative to prior metrics and ESPC Demonstration goals

Define a scorecard of validation metrics for all components of the coupled system. Initially perform validation testing of the coupled system using existing metrics, however, definition of new metrics may be required to examine the exchange processes at the various interfaces. Conduct validation relative to the national ESPC demonstrations.

\section{WORK COMPLETED}

Work area: Design infrastructure for operational implementation for coupled system

Task 1: Define implementation across operational systems, architecture requirements, cycling setup including $D A$.

The operational implementation design document was submitted at the end of the last fiscal year. At the request of the sponsor, it was then sent to the operational centers (NAVOCEANO and FNMOC) for review and their commentary was incorporated into the document. A final version appeared in print in February 2014 as an NRL Memorandum Report (Metzger et al., 2014).

\section{Task 2: Develop infrastructure to run NAVGEM/HYCOM with DA}

The cycling of the coupled atmosphere-ocean-ice system along with the associated data assimilation is defined in Figure 1 for NAVGEM and in Figure 2 for HYCOM+CICE. Currently these are the only model components that are working coupled together.

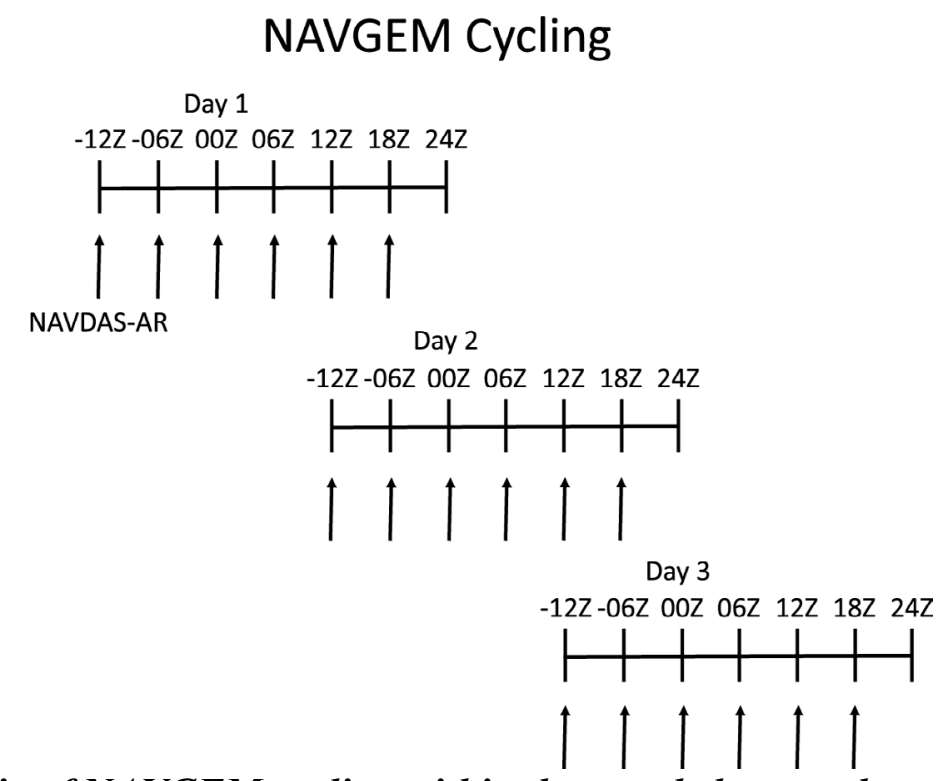

Figure 1: A schematic of NAVGEM cycling within the coupled atmosphere-ocean-ice system. The NAVDAS-AR data assimilation will occur every six hours. The initial run will need to occur at $-12 Z$ because that is the starting point for HYCOM+CICE each day. 


\section{HYCOM/CICE Cycling}

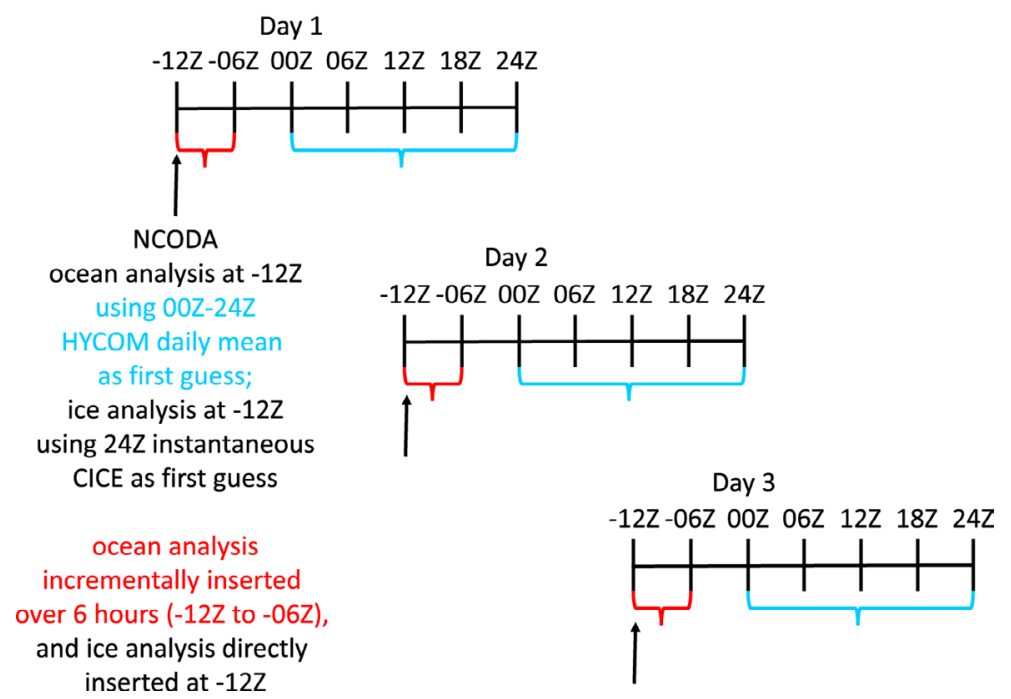

Figure 2: A schematic of HYCOM+CICE cycling within the coupled atmosphere-ocean-ice system. The NCODA ocean and ice analyses will occur once per day at -12Z. The ocean model needs to run to $+24 Z$ because NCODA uses the 00Z-24Z HYCOM daily mean as the first guess for the ocean analysis and the $24 Z$ instantaneous CICE field as the first guess for the ice analysis.

Timing estimates have been refined for the integration of a NAVGEM (T350L50) - NAVDAS / HYCOM+CICE $\left(1.12^{\circ}\right)$ - NCODA reanalysis using 1000 IBM iDataPlex processors. The total walltime for a single day is 282 minutes, or 71.7 days for a year of integration.

An NCODA analysis for WAVEWATCH III (WW3) presently runs at FNMOC, but there is no wave analysis running on the Navy DSRC and so it is a missing data assimilation component of the coupled atmosphere-ocean-ice-waves system. FNMOC provided guidance to NRL-SSC on how to implement NCODA for the assimilation of altimeter data into WW3 inputs. Progress has been made converting WW3 output files to an NCODA-ready format, the first step of the process. The question of altimeter data availability in real-time is still not fully resolved and is being investigated. Work on completeing the scripting continues.

\section{Task 3: Scripting implementation}

In the coming year the control of the coupled system will be converted from a specialized script to a series of modular re-runnable tasks for control by a scheduler of the user's choosing. These tasks will follow general good practice and follow the strategy used by other major operational centers. An archive of the $00 \mathrm{Z}$ initial conditions from the FNMOC operational run will be maintained on the Navy DSRC, these can be used to test various aspects of the developing system to ensure their functionality across a range of conditions (states). A meta-schedular suite prototype has been designed and is being tested, and the first skeleton has been validated. The meta-schedular allows for a greater control of the tasks interoperability and more efficient running and monitoring of tasks than using a "pure" scripting language such as korn or bash. An example of one of these higher level tools is SMS which is being used opeationally at FNMOC. A diagram of the ESPC control suite is shown below in Figure 3, this is 
produced directly from the control file by the meta-scheduler which in this case is called "cylc". Various colors indicate the pre-processing, forecast, and post-processing steps. Double lines around the fields indicate the task is a family which contains sub-tasks that means there are independent atmospheric, ocean and sea ice components. At this time NAVGEM, HYCOM and CICE are being run but the addition of WW3 into this framework is in prinicple a straightforward incorporation.
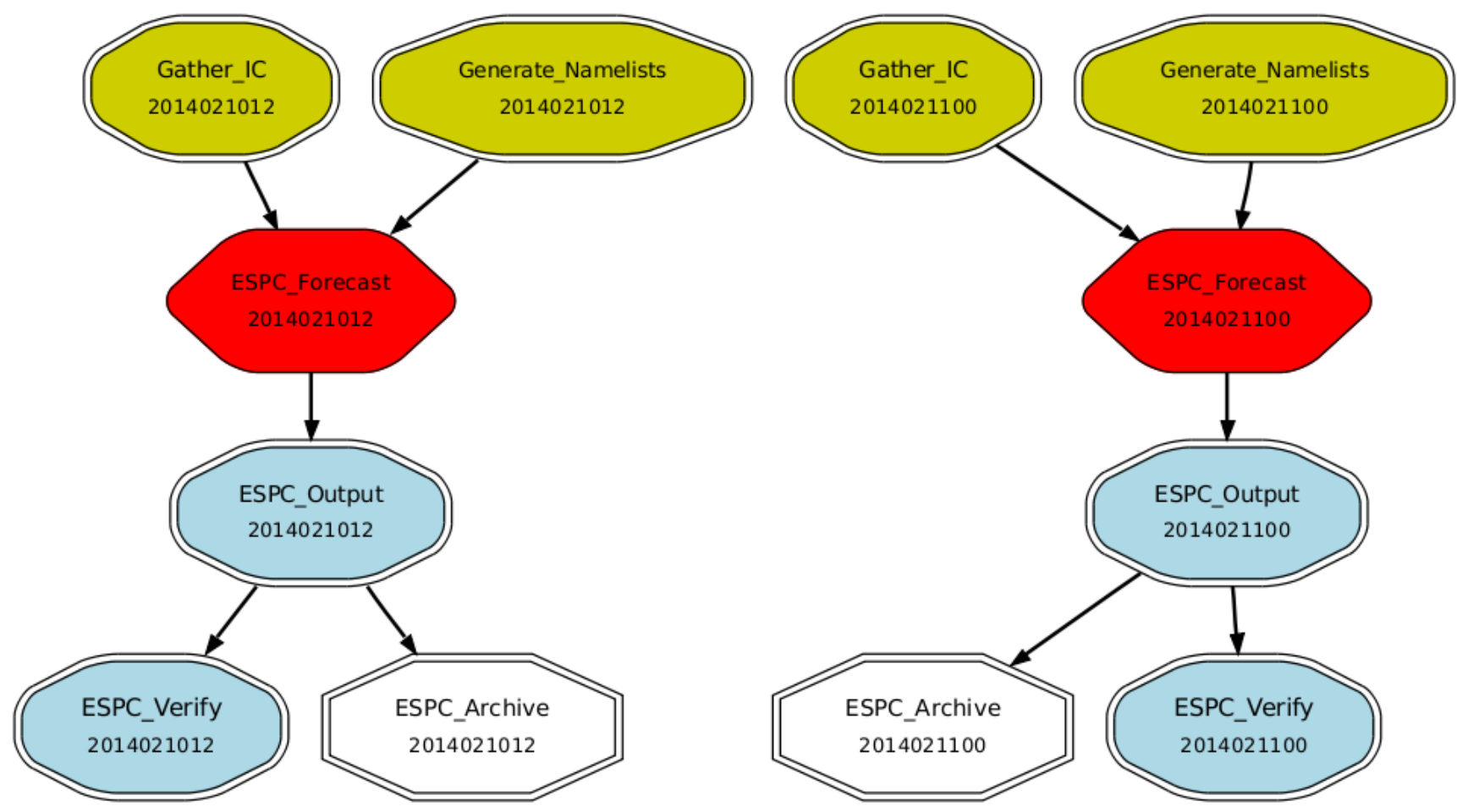

Figure 3: A graph of the suite control file for the ESPC system. This diagram was produced by the cylc meta-scheduler which is now being testing as the task management system for the ESPC system. The different colors indicate pre-processing (green), forecast (red), and post-processing (blue), while white indicates a non inter-dependent task.

Work area: Validation testing relative to prior metrics and ESPC Demonstration goals

Task 1: Given the long term reforecasts constructed in the ESPC development work, gather historical data sets.

This year, NRL-SSC completed a 1993-2012 Ocean Reanalysis using 1/12 ${ }^{\circ}$ global HYCOM-NCODA. As part of the preparatory work for that hindcast, all the necessary satellite altimeter, ice concentration and sea surface temperature data, in-situ profile data (Argo profiling floats, XBTs, CTDs), moored and drifting data have been gathered, quality controlled and put into NCODA-ready format. Beyond this period these data are routinely gathered to be used as part of the Global Ocean Forecast System (GOFS). Thus, all the required input observational datastreams should be in place for the ocean and ice components of a long-term coupled reforecast.

NRL-MRY continues to archive the atmospheric data which extends an archive spanning back to November 2008. This atmospheric DA now processes over 100 million observations and assimilates operationally over 3 million. In the coming year an extension of the archive is possible; however, the 
time to gather the data types will be extensive as the distinct data types number over 100 which populate 49 distinct directories. The current volume is roughly $32 \mathrm{~Gb}$ per day for these various data. A reanalysis covering a single year is being planned which can be used to exercise the various coupling infrastructure components. A reanalysis employing the full 5 year archive will be undertaken as the various components and the forecasts are verified.

\section{Task 2: Evaluation of coupled runs using prior metrics.}

We have begun the process of designing integrated skill diagnostics for the HYCOM+CICE component of ESPC, starting with the previous ocean-ice validation test reports that have been used to evaluate earlier systems. These reports are being used to compile a list of metrics and associated data sources for consideration with this system. We have begun researching and designing oceanic metrics with the longer range forecasts ( $\sim 90$ days) of ESPC in mind, instead of the shorter range ( $\sim 7-14$ days) of earlier systems. These metrics will focus on longer term dynamics such as key boundary layer transports, main thermocline displacement and overturning circulations instead of the shorter time scale upper ocean metrics traditionally used. We have begun examining the distribution and types of data routinely available for assimilation into HYCOM and CICE, in order to better to understand the challenges in designing integrated skill diagnostics for the poorly observed ocean. Further research using the existing scientific literature and discussions with team members, external scientists experienced with coupled modeling and operational centers are planned in FY15 to help define a state of the art approach for routinely monitoring the performance of the coupled ESPC system.

\section{Task 3: Development of metrics to ESPC demonstrations as related to Navy activities}

Item IV: Validation of Arctic ice formation/melt:

Sea Ice Prediction Network (SIPN) forecasts were completed using a test version of the ESPC global coupled atmosphere-ocean-ice system. The SIPN is a multi-model comparison of September Arctic sea ice extent forecasts with lead times of 30 to 90 days. NAVGEM versions 1.1 and 1.2 were coupled with HYCOM version 2.2.77i, and CICE version 4. The forecasts started on June 30th 12Z 2014 and July 31 st 12 Z 2014 with restart files from the individual assimilative model components. No data assimilation or cycling was performed for these forecasts (i.e. cold starts). Model horizontal grid resolution was T359L50 for NAVGEM 1.1/1.2, 9 $\mathrm{km}$ (at the equator) for HYCOM and $\sim 3.5 \mathrm{~km}$ (at the North Pole) for CICE. Diagnostics were performed against FNMOC's sea ice concentration data set, which is the same data set used for CICE assimilation. The model forecasts were un-tuned, i.e. no heat flux corrections were used.

\section{RESULTS}

\section{Work area: Validation testing relative to prior metrics and ESPC Demonstration goals}

\section{Task 2: Evaluation of coupled runs using prior metrics.}

Through evaluation of some of the coupled atmosphere-ocean-ice experiments, it was learned that the atmospheric scorecard will have to be modified to take into account more metrics that evaluate processes at or near the air-ocean interface. For example, some of the initial coupled 30-day forecasts had a tendency to develop far too many and too strong tropical cyclones in the Indo-West Pacific basins. This propensity for excessive storms was not detected using the traditional $500 \mathrm{hPa}$ height 
anomaly metric or other atmospheric scorecard metrics, but was very evident using a newly defined cyclonic vorticity at $850 \mathrm{hPa}$ metric.

Task 3: Development of metrics to ESPC demonstrations as related to Navy activities

Item IV: Validation of Arctic ice formation/melt:

The ESPC global atmosphere-ocean-ice forecasts are comparable to the other numerical models in the SIPN (Figure 4). The minimum September Arctic sea ice extent for the forecasts starting on June 30th 12Z 2014 was 4.3 million $\mathrm{km}^{2}$ for the NAVGEM v1.1 - HYCOM - CICE run and 4.5 million $\mathrm{km}^{2}$ for the NAVGEM v1.2 - HYCOM - CICE system. Model forecasts with the start date of July 31st $12 \mathrm{Z}$ 2014 had a minimum September Arctic sea ice extent of 4.8 and 4.5 million $\mathrm{km}^{2}$ for the system using NAVGEMv1.1 and NAVGEMv1.2 respectively. September sea ice minimum extents for the SIPN models ranged from 4.1 to 5.6 million $\mathrm{km}^{2}$. According to the National Snow and Ice Data Center, a 2014 Arctic sea ice minimum of 5.02 million $\mathrm{km}^{2}$ was reached on 19 September.

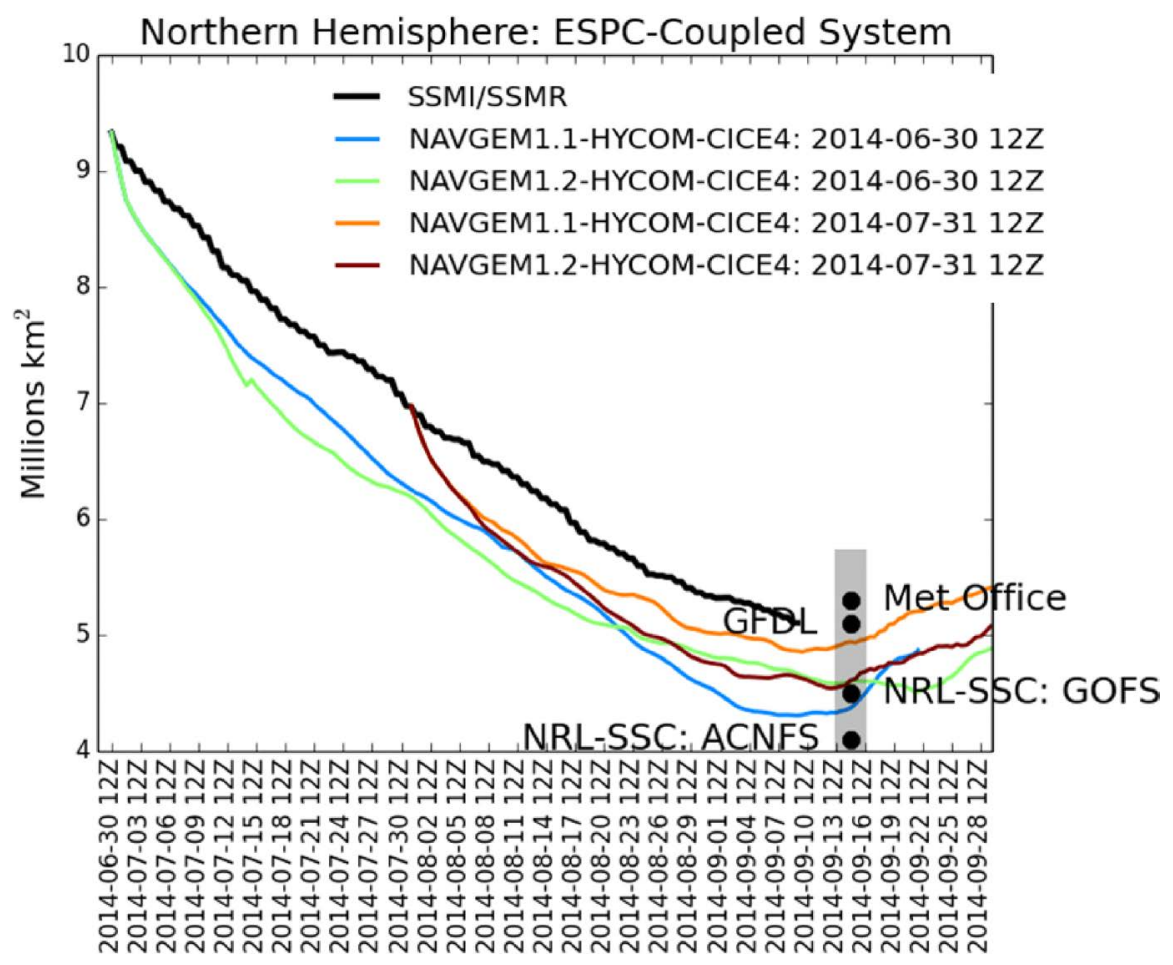

Figure 4: Observed (black) Northern Hemisphere/Arctic sea ice extent $\left(\mathrm{Mkm}^{2}-\right.$ defined as $15 \%$ ice concentration and greater) during the 2014 melt season vs. sea ice extent from a suite of coupled NAVGEM-HYCOM-CICE forecasts started from 30 June 2014 atmosphere-ocean-ice initial conditions (ICs) (blue/green) and from 31 July 2014 ICs (orange/burgundy). Different versions of NAVGEM (1.1 vs. 1.2) were used in the forecasts. The black dots indicate sea ice extent forecasts from specific modeling systems and the gray bar is the range for all the SIPN

modeling systems that submitted reports. The 2014 minimum sea ice extent had not yet been reached when this graphic was generated. 
Though the September minimum Arctic sea ice extents are comparable to other models, the initial decrease of sea ice at the beginning of each forecast may be an issue and will be investigated further. In addition, these forecasts were compared to observations in the southern hemisphere ( $\mathrm{SH})$. $\mathrm{SH}$ analysis suggests that the coupled system has a similar sea ice extent for the first five forecast days, but unrealistic increases in sea ice occur on longer time scales. These long-range biases may be caused by NAVGEM's cold bias over sea ice during the polar night.

\section{IMPACT/APPLICATIONS}

ESPC forecasts will provide environmental information to meet Navy and DoD operations and planning needs throughout the globe from under the sea to the upper atmosphere, and from the tropics to the poles.

\section{RELATED PROJECTS}

Dependence on outside 6.2 work: ONR-funded MJO DRI; ONR-funded ITOP; ONR-funded Tropical Cyclone; ONR-funded Unified Physical Parameterization DRI; ONR-funded Seasonal Prediction DRI; NOPP-funded HYCOM; NOPP-funded waves work; NRL-funded high resolution ice coupling; NRLfunded MJO 6.2; NRL-funded Fresh Water Fluxes 6.2; NRL-funded Wave conservation 6.2.

Dependence on outside 6.4 work: The NUOPC interoperability layer under ESMF is a critical piece on which this development initially built upon. Large Scale Atmospheric Modeling (under 6.4 NAVGEM) is providing extensions and validation to NAVGEM. Large Scale Ocean Modeling is providing extensions and validation to HYCOM. Small Scale Ocean Modeling is providing extensions and validation to WaveWatch III. Ocean Data Assimilation is providing vertical synthetic covariance and data assimilation for HYCOM and new data streams from altimeter satellites. Atmospheric Data Assimilation is providing extensions and validation to NAVGEM assimilation. Satellite Ice is providing new data streams for assimilation in CICE.

\section{REFERENCES}

Metzger, E.J., B.C. Ruston, J.D. Dykes, T.R. Whitcomb, A.J. Wallcraft, L.F. Smedstad, S. Chen and J. Chen, 2014: Operational implementation design for the Earth System Prediction Capability (ESPC): A first-look. NRL Memo. Rpt., NRL/MR/7320--14-9498, 21 pages. Available at http://www7320.nrlssc.navy.mil/pubs.php. 